\title{
Electron Transfer in Peptides: The Influence of Charged Amino Acids**
}

\author{
Jian Gao, Pavel Müller, Min Wang, Sonja Eckhardt, Miriam Lauz, Katharina M. Fromm, and \\ Bernd Giese*
}

Long-range electron transfer (ET) through proteins is a fundamental reaction in living organisms, playing a role in energy-conversion processes like photosynthesis ${ }^{[1 \mathrm{a}]}$ and respiration $^{[1 b]}$ as well as in enzymatic reactions. ${ }^{[1 c]}$ The mechanism of these ET processes is still a matter of controversy. Two cases are discussed, a bridge-mediated superexchange (single-step reaction) and a hopping mechanism (stepwise reaction). ${ }^{[2]}$ Today, the hopping mechanism, where each step follows the Marcus rule, ${ }^{[3]}$ is favored for long-range ET through peptides. ${ }^{[4]}$ Nevertheless, for special conformations like $\alpha$ helices with their intramolecular hydrogen bonds, experiments on long-range ET have been discussed as single-step reactions. ${ }^{\left[{ }^{[]}\right.}$However, quantum chemical calculations favor a multistep reaction also in $\alpha$ helices. ${ }^{[6]}$ For the polyproline II helix (PPII helix), which does not have hydrogen bonds, a mechanistic transition between a singlestep and a stepwise reaction was observed when the number of the proline units between the electron donor and the electron acceptor is larger than 4. ${ }^{[7]}$ Quantum chemical calculations explain the effect of peptide conformations on the distance influence of ET by a pathway model. ${ }^{[8]}$ Recently it was shown that the rate also depends upon the direction of the ET process, demonstrating the important impact of dipole moments. ${ }^{[9]}$ Another parameter influencing ET is the charge of ions bound as cofactors to the systems. ${ }^{[10]}$ Such a Coulomb effect should also be of importance in peptides with unprotected amino or carboxylate groups that exist as ions under biological conditions. Herein we present our new results, which demonstrate that ET in peptides is indeed influenced by their charged termini.

The investigations were carried out with our recently developed model peptides $\mathbf{1}$ in which ET occurs between the radical cation of a dialkoxyphenyl group (electron acceptor at the C-terminal end) and tyrosine as the electron donor at the $\mathrm{N}$-terminal end. Halfway between the donor and the acceptor we introduced an amino acid with a side chain $X .{ }^{[1]}$ These

[*] Dr. J. Gao, Dr. P. Müller, Dr. M. Wang, Prof. Dr. B. Giese

Department of Chemistry, University of Basel

St. Johanns-Ring 19, 4056 Basel (Switzerland)

E-mail: bernd.giese@unibas.ch

Dr. S. Eckhardt, Dr. M. Lauz, Prof. Dr. K. M. Fromm

Department of Chemistry, University of Fribourg

Chemin du Musée 9, 1700 Fribourg (Switzerland)

[**; This work was supported by the Swiss National Science Foundation and the Adolphe Merkle Institute (AMI). We are grateful to Prof. M. Michel-Beyerle for very helpful discussions. three amino acids were separated by sequences of three prolines (Scheme 1). If $\mathrm{X}$ is a side chain that can be oxidized by the electron acceptor, this central amino acid acts as a stepping stone for a hopping process (relay amino acid). ${ }^{[11]}$

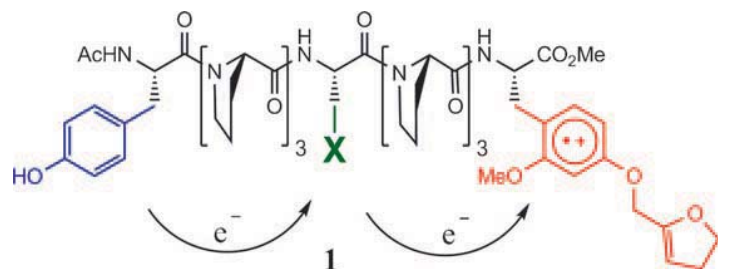

Scheme 1. Model peptide 1 for the investigation of intramolecular ET with $\mathrm{X}$ as side chain of an amino acid that is used as relay station. ET occurs through the peptide backbone.

The structure of peptides 1 (in $\mathrm{CH}_{3} \mathrm{CN} / \mathrm{H}_{2} \mathrm{O}$ 3:1) was characterized by their CD spectra as PPII helices. ${ }^{[12]}$ Interestingly, the $\mathrm{CD}$ spectra remained unchanged when the temperature was varied between $20^{\circ} \mathrm{C}$ and $80^{\circ} \mathrm{C}$, which supports the conformational stability of the peptides. These findings are in agreement with experimental and theoretical data from other polyproline systems. ${ }^{[13,14]}$ In a PPII helix each of the triproline spacers corresponds to a distance of about $10 \AA .^{[13,14]}$ The triproline units thus separate the donor, the acceptor, and the relay amino acids, and act as a medium for the ET process. The ${ }^{13} \mathrm{C}$ NMR spectra ${ }^{[15,16]}$ indicate that approximately $80 \%$ of the proline peptide bonds adopt a trans conformation. The remaining signals are in agreement with a cis conformtion of at least one peptide bond. In general, the tendency of proline peptide bonds to form cis linkages is increased by participating aromatic amino acids. ${ }^{[17]}$ In order to keep the conformations of the peptides used in our experiments as similar as possible, all peptides $(\mathbf{2}-\mathbf{5}, \mathbf{1 0}$, and 11) have the same type of amino acid sequence: one aromatic amino acid at the Cterminal as well as the $\mathrm{N}$-terminal end, and one aromatic amino acid in the middle of the peptide. These aromatic amino acids were separated by triproline spacers. In addition, all experiments were carried out in the same solvent mixture $\left(\mathrm{CH}_{3} \mathrm{CN} / \mathrm{H}_{2} \mathrm{O}\right.$ 3:1). ${ }^{[18]}$ With peptides 1 we had already confirmed that a) a stepwise process is faster than a onestep reaction, ${ }^{[11 a]}$ b) certain amino acids can act as relay stations (stepping stones) in a stepwise (hopping) process, ${ }^{[11 \mathrm{~b}]}$ and c) ET rates depend upon the direction along the peptide backbone. ${ }^{[11 c]}$ Now this system was used to determine the influence of an ammonium group on ET processes between and through peptides. 
a)

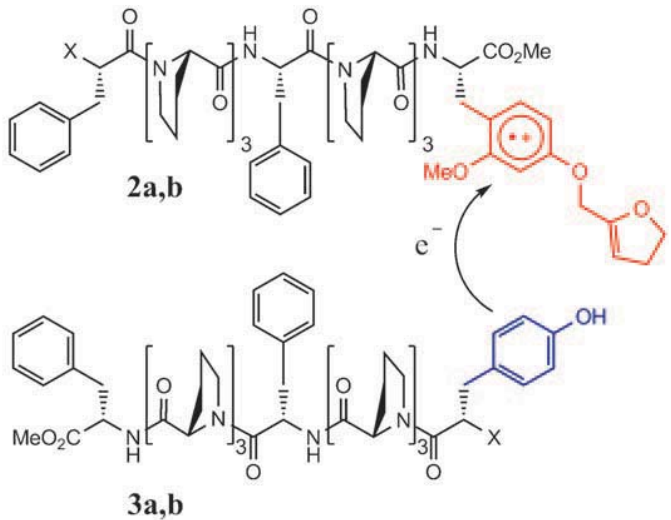

$$
\begin{array}{ll}
\text { a: } \mathrm{X}=\mathrm{NHAc} & k_{\mathrm{ET}}=(4.4 \pm 0.5) \times 10^{8} \mathrm{M}^{-1} \mathrm{~s}^{-1} \\
\text { b: } \mathrm{X}=\mathrm{NH}_{3}^{+} \mathrm{TFA}^{-} & k_{\mathrm{ET}}=(1.5 \pm 0.1) \times 10^{8} \mathrm{M}^{-1} \mathrm{~s}^{-1}
\end{array}
$$

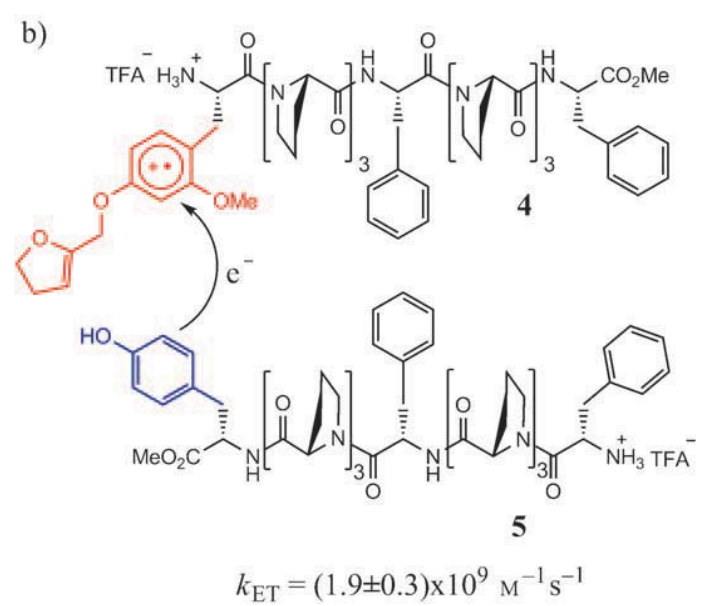

Scheme 2. Rate of intermolecular ET ( $\left.k_{\mathrm{ET}}\right)$ between a) peptides $\mathbf{2} \mathbf{a}, \mathbf{b}$ (acceptor in red) and $\mathbf{3} \mathbf{a}, \mathbf{b}$ (donor in blue), and b) peptides $\mathbf{4}$ (acceptor in red) and $\mathbf{5}$ (donor in blue). $\mathrm{TFA}^{-}=\mathrm{CF}_{3} \mathrm{COO}^{-}$.

We first measured the charge effect on intermolecular ET reactions for three pairs of peptides (Scheme 2). One peptide contained only the electron acceptor (2a,b and 4), and the other only the electron donor (3a,b and 5). ${ }^{[19]}$ Intramolecular ET through these peptides could not occur since the other amino acids (proline and phenylalanine) cannot be oxidized because of their high redox potentials.

The generation of electron acceptors $\mathbf{2} \mathbf{a}, \mathbf{b}$ and $\mathbf{4}$ followed a procedure that we had developed earlier (Scheme 3):
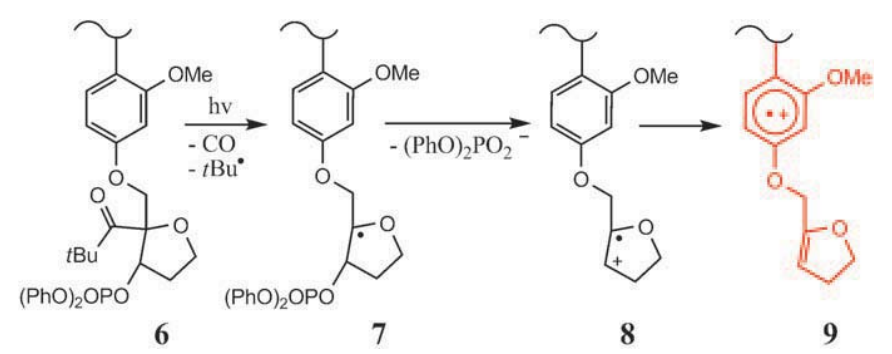

Scheme 3. Generation of the charged electron acceptor 9 by laser flash photolysis of 6 . photoexcitation (excimer laser at $308 \mathrm{~nm}$, see the Supporting Information) of the side chain 6 yielded a Norrish I type reaction product $\mathbf{7}$, which undergoes a heterolytic $\beta$ elimination $(\mathbf{7} \rightarrow \mathbf{8})$. Subsequent oxidation leads to the radical cation $\mathbf{9}$, which is the electron acceptor in peptides $\mathbf{2} \mathbf{a}, \mathbf{b}$ and $\mathbf{4}^{[19,20]}$ Tyrosine in peptides $\mathbf{3 a} \mathbf{a}, \mathbf{b}$ and $\mathbf{5}$ is the electron donor that becomes oxidized and deprotonated to the tyrosyl radical during the ET process.

We determined intermolecular ET rates between the peptides by laser experiments. Radical cations $\mathbf{2 a , b}$ and 4 $\left(\lambda_{\max }=450 \mathrm{~nm}\right)$, which oxidized $\mathbf{3 a} \mathbf{a}, \mathbf{b}$ and $\mathbf{5}$ to the respective tyrosyl radicals $\left(\lambda_{\max }=408 \mathrm{~nm}\right)$, were generated by a laser flash, and the transient absorption spectra were recorded after a defined time delay (40-1000 ns). ${ }^{[20]}$ The concentrations of the reactive intermediates could be determined from the original spectra in MATLAB, using the algorithm of Gamp et al. (see the Supporting Information). ${ }^{[21]}$ Each laser flash $(\mathbf{6} \rightarrow \mathbf{9})$ generated only small amounts of $\mathbf{2 a , b}$ and $\mathbf{4}$, so that peptides $\mathbf{3 a}$ a,b and $\mathbf{5}$ were always in large excess. Therefore, these data could be analyzed by a pseudo-first-order kinetics using SPECFIT (see the Supporting Information). ${ }^{[22]}$ The second-order rate constants shown in Scheme 2 were deduced from the pseudo-first-order rates using the concentrations of $\mathbf{3 a}, \mathbf{b}$ or $\mathbf{5}$. The rates demonstrate that a protonated amino group either slows down (reaction: $\mathbf{2} \mathbf{b}+\mathbf{3} \mathbf{b}$ compared to $\mathbf{2} \mathbf{a}+$ 3a) or speeds up (reaction: $\mathbf{4}+\mathbf{5}$ ) intermolecular ET between peptides. This rate effect is caused by the different Coulomb energies between the charges. The ET rate decreases if the positive charge is situated close to the electron-donor tyrosine which releases a proton during oxidation (peptide $\mathbf{3 b}$ ). In contrast, the rate increases if the ammonium group is in the vicinity of the positively charged electron acceptor which gains an electron during the ET step (peptide 4). With our model peptides 2-5 the position of the ammonium ion leads to a 13-fold increase of the rate of intermolecular ET from $1.5 \times$ $10^{8} \mathrm{M}^{-1} \mathrm{~s}^{-1}$ (reaction: $\mathbf{2 b}+\mathbf{3 b}$ ) to $1.9 \times 10^{9} \mathrm{M}^{-1} \mathrm{~s}^{-1}$ (reaction: $4+5)$.

In order to determine how a charge influences intramolecular ET processes we used peptides $10 \mathbf{a}, \mathbf{b}$ and $\mathbf{1 1} \mathbf{a}, \mathbf{b}^{[23]}$ where ET occurs in a two-step reaction (Schemes 4 and 5). ${ }^{[1]}$

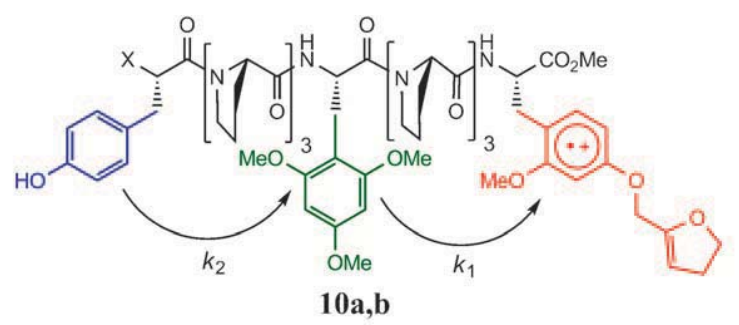

a: $\mathrm{X}=\mathrm{NHAc} \quad k_{2}=(3.0 \pm 1.3) \times 10^{7} \mathrm{~s}^{-1} \quad k_{1}=(3.3 \pm 0.5) \times 10^{6} \mathrm{~s}^{-1}$ b: $\mathrm{X}=\mathrm{NH}_{3}^{+} \mathrm{TFA}^{-} \quad k_{2}=(7.5 \pm 1.8) \times 10^{6} \mathrm{~s}^{-1} \quad k_{1}=(2.5 \pm 0.3) \times 10^{6} \mathrm{~s}^{-1}$

Scheme 4. Intramolecular ET through peptides 10a,b (acceptor in red, donor in blue, relay in green). Peptide 10 a carries protected $\mathrm{N}$ - and $\mathrm{C}$ terminal amino acids; peptide $10 \mathrm{~b}$ carries an unprotected, protonated $\mathrm{N}$-terminal amino acid. In $10 \mathrm{~b}$ the electron donor (blue) is the side chain of the protonated $\mathrm{N}$-terminal amino acid. The rate constants for the hopping process are $k_{1}$ and $k_{2}$. 
Again the oxidized dialkoxyphenyl group 9 acts as the electron acceptor, and tyrosine as the electron donor. Trimethoxyphenylalanine, situated between the donor and the acceptor, is a relay amino acid that operates as the electron donor in the first ET step $\left(k_{1}\right)$; it is oxidized to its radical cation $\left(\lambda_{\max }=550 \mathrm{~nm}\right)$ and then serves as the electron acceptor in the second hopping step $\left(k_{2}\right)$.

We started our experiments on intramolecular ET with protected peptides $\mathbf{1 0} \mathbf{a}$ and $\mathbf{1 1}$ a by measuring the relative concentrations of the three reactive intermediates between 30 and $500 \mathrm{~ns} .^{[24]}$ In order to determine the rate constants $k_{1}$ and $k_{2}$ of the intramolecular hopping steps, the rates of the intermolecular reactions were subtracted from the observed data. ${ }^{[25]}$ The resulting hopping rates in the neutral peptide $\mathbf{1 0} \mathbf{a}$ (Scheme 4) demonstrate that the first ET step $\left(k_{1}\right)$ between the trimethoxyphenyl side chain of the relay amino acid and the dialkoxyphenyl radical cation is about 10 times slower than the second ET step $\left(k_{2}\right)$ where tyrosine is the electron donor. This reflects the differences in the redox potentials of the involved aromatic side chains. ${ }^{[11 a]}$

For peptide 11a (Scheme 5), only the rate of the first ET step $\left(k_{1}\right)$ could be determined since the concentration of the intermediate trimethoxyphenyl radical cation was too low for a reliable determination of $k_{2}$ (see the Supporting Informa-

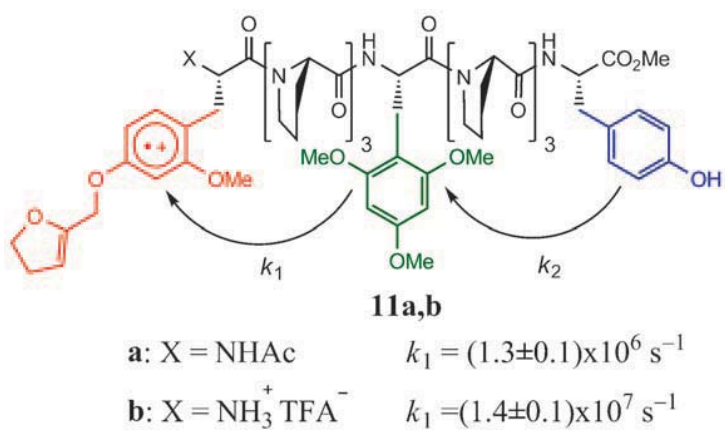

Scheme 5. Intramolecular ET through peptides 11 a,b (acceptor in red, donor in blue, relay in green). Peptide 11 a carries protected $\mathrm{N}$ - and $\mathrm{C}$ terminal amino acids; peptide $11 \mathrm{~b}$ carries an unprotected, protonated $\mathrm{N}$-terminal amino acid. In $11 \mathrm{~b}$ the electron acceptor (red) is the side chain of the protonated amino acid. Only the rate constant $k_{1}$ of the first hopping step could be measured.

tion). In peptide $\mathbf{1 0} \mathbf{a}$ the ET rate constant $k_{1}$ is 2.5 times faster than in peptide 11a. This is in agreement with the calculated dipole moment of a PPII helix, which is small but has its negative end at the N-terminal amino acid. ${ }^{[14]}$ Thus in a PPII helix, ET in the direction $\mathrm{N} \rightarrow \mathrm{C}(\mathbf{1 0 a})$ is faster than in the opposite direction (11a).

Next, we synthesized peptides containing an ammonium group at the $\mathrm{N}$-terminal amino acid, ${ }^{[23,26]}$ and generated the radical cations $\mathbf{1 0 b}$ and $\mathbf{1 1 b}$ by a laser flash. ${ }^{[27]}$ The transient absorption spectra between 400 and $600 \mathrm{~nm}$ were recorded between 30 and $500 \mathrm{~ns}$ after the laser flash, and the relative concentrations of all three reactive intermediates were determined from the experimental data in MATLAB. ${ }^{[21]}$ Kinetic analysis by SPECFIT ${ }^{[22]}$ yielded rate data (see the Supporting Information) that had to be corrected by consid- eration of the intermolecular rates. ${ }^{[25]}$ The corrected intramolecular ET rate constants for the hopping steps are shown in Schemes 4 and 5. The experimental errors for the $k_{1}$ data of the first ET steps are small enough that they can be used for a detailed discussion. The $k_{1}$ data of $\mathbf{1 0} \mathbf{a}$ and $\mathbf{1 0 b}$ in Scheme 4 are identical within experimental error. This demonstrates that the positive charge of an ammonium ion at the $\mathrm{N}$ terminal amino acid does not influence the distal ET hopping step between the relay amino acid and the C-terminal amino acid. In contrast to this, an ammonium ion increases the rate of the proximate ET step from the relay amino acid to the $\mathrm{N}$ terminal amino acid by one order of magnitude (Scheme $5 ; k_{1}$ : $11 \mathbf{b}$ versus 11a). This influence of the ammonium ion on the ET rate is caused by a change of the Coulomb repulsion between the positive charges during the ET reaction. Compound 11a carries only one positive charge, which is shifted during the ET step along the protected neutral peptide backbone (Scheme 5). Thus, the Coulomb energy remains more or less unchanged. Contrary to this, in peptide $\mathbf{1 1 b}$ two positive charges are close to each other before the ET step, and they are far from each other after the ET step $(\mathbf{1 2} \rightarrow \mathbf{1 3}$ in Scheme 6). The distance between the ammonium group and the electron acceptor in $\mathbf{1 1 b}$ is $r_{1}$. This raises the ground-state free energy of $\mathbf{1 1 b}$ by the Coulomb repulsion energy $e^{2} / 4 \pi \varepsilon r_{1}$, where $\varepsilon$ is the effective static dielectric constant of the medium between and around the charges, and $e$ is the electric charge.

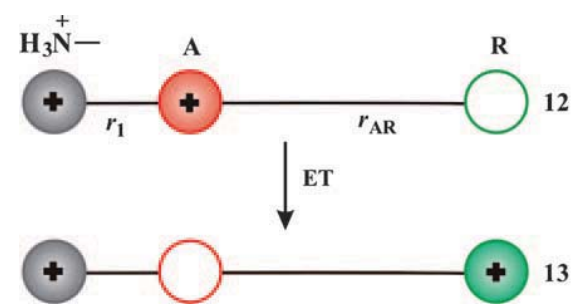

Scheme 6 . Schematic representation $(12 \rightarrow 13)$ for the first ET step $\left(k_{1}\right.$ in peptide $11 \mathrm{~b}$ ) with $\mathrm{A}$ being the electron acceptor and $\mathrm{R}$ the relay amino acid. During this ET the distance between the positive charges increases from $r_{1}$ to $r_{1}+r_{\mathrm{AR}}$.

For an estimation of the Coulomb repulsion energy in $\mathbf{1 1 b}$ we have used a distance $r_{1}$ of $3 \AA$ between the positive charges of the ammonium ion and the aromatic radical cation. ${ }^{[28]}$ The dielectric constant was set to 40 , which is the $\varepsilon$ value for a $3: 1$ $\mathrm{CH}_{3} \mathrm{CN} / \mathrm{H}_{2} \mathrm{O}$ mixture. ${ }^{[29]}$ This leads to a Coulomb repulsion energy of $2.8 \mathrm{kcal} \mathrm{mol}^{-1}$. Thus, the ground-state free energy $\Delta G^{0}$ of $\mathbf{1 1 b}$ is increased by this amount relative to $\mathbf{1 1 a}$. These $2.8 \mathrm{kcalmol}^{-1}$ speed up only the proximate ET step $\left(k_{1}\right.$ in Scheme 5), because the distal ET step is no longer influenced by the positive charge at the $\mathrm{N}$-terminal amino acid (see discussion above, and $k_{1}$ in Scheme 4). Consequently, the first ET step $k_{1}$ of $\mathbf{1 1} \mathbf{b}$ (Scheme 5) is $2.8 \mathrm{kcal} \mathrm{mol}^{-1}$ more exergonic than that of 11a. This difference in the standard free energy $\Delta G^{0}$ can be correlated to the difference of the activation free energy $\Delta G^{*}$ by applying the Marcus theory. ${ }^{[3]}$ It predicts a linear dependence of the activation free energy $\Delta G^{*}$ on $\Delta G^{0}$ / 2 for the case where $\left|\Delta G^{0} / \lambda\right|$ is small ( $\lambda$ is the reorganization 
energy). In our system this condition is fulfilled for the first ET steps $\left(k_{1}\right)$ in $\mathbf{1 1 a}, \mathbf{b}$ as the two alkoxy-substituted aromatic side chains have similar redox potentials such that the $\Delta G^{0}$ values are very small. ${ }^{[11 a]}$ With a change of the Coulomb energy of $2.8 \mathrm{kcal} \mathrm{mol}^{-1}$, a difference of $1.4 \mathrm{kcal} \mathrm{mol}^{-1}$ for the activation free energy $\Delta G^{*}$ between ET in $\mathbf{1 1 b}$ and $\mathbf{1 1 a}$ results. According to the Gibbs equation a $1.4 \mathrm{kcal} \mathrm{mol}^{-1}$ difference of $\Delta G^{*}$ changes the rate by a factor of about 10 $\left(25^{\circ} \mathrm{C}\right)$. This is in excellent agreement with our measured value ( $k_{1}$ : 11b versus 11a). The Coulomb energy depends drastically upon the dielectric constant. In proteins and enzymes, where ET occurs in peptide regions that are not solvated by bulk water, the $\varepsilon$ values could be smaller than for a $\mathrm{CH}_{3} \mathrm{CN} / \mathrm{H}_{2} \mathrm{O}$ solvent mixture. Therefore, the charge effect on ET rates might be even more pronounced in biological systems than in our model peptides.

Conclusion: Protonated amino groups in peptides either increase or decrease ET rates. This effect is explained by the influence of the Coulomb energy on the activation free energy according to the Marcus theory. It has to be seen whether nature uses basic and/or acidic amino acids to control ET rates or even the ET direction in proteins.

[1] For recent reviews, see: a) S. Eberhard, G. Finazzi, F. A. Wollmann, Annu. Rev. Genet. 2008, 42, 463; b) M. Cordes, B. Giese, Chem. Soc. Rev. 2009, 38, 892; c) J. Stubbe, D. G. Nocera, C. S. Yee, M. C. Y. Chang, Chem. Rev. 2003, 103, 2167.

[2] For recent reviews, see: a) H. B. Gray, J. R. Winkler, Chem. Phys. Lett. 2009, 483, 1; b) B. Giese, M. Graber, M. Cordes, Curr. Opin. Chem. Biol. 2008, 12, 755; c) Y.-T. Long, E. Abu-Irhayen, H.-B. Kraatz, Chem. Eur. J. 2005, 11, 5186.

[3] R. A. Marcus, Angew. Chem. 1993, 105, 1161; Angew. Chem. Int. Ed. Engl. 1993, 32, 1111.

[4] See for example: C. Shih, A. K. Museth, M. Abrahamsson, A. M. Blanco-Rodriguez, A. J. Di Bilio, J. Sudhamsu, B. R. Crane, K. L. Ronayne, M. Towrie, A. Vlceck, J. H. Richards, J. R. Winkler, H. B. Gray, Science 2008, 320, 1760; S. Y. Reece, M. R. Seyedsayamdost, J. Stubbe, D. G. Nocera, J. Am. Chem. Soc. 2007, 129, 13828; E. W. Schlag, S.-Y. Sheu, D.-Y. Yang, H. L. Selzle, S. H. Lin, Angew. Chem. 2007, 119, 3258; Angew. Chem. Int. Ed. 2007, 46, 3196; K. Yanagisawa, T. Morita, S. Kimura, J. Am. Chem. Soc. 2004, 126, 12780; T. Carell, L. T. Burgdorf, L. M. Kundu, M. Cichon, Curr. Opin. Chem. Biol. 2001, 5, 491; C. Aubert, M. H. Vos, P. Mathis, A. P. M. Eker, K. Brettel, Nature 2000, 405, 586; E. W. Schlag, D.-Y. Yang, S.-Y. Sheu, H. L. Selzle, S. H. Lin, P. M. Rentzepis, Proc. Natl. Acad. Sci. USA 2000, 97, 9849; C. C. Page, C. C. Moser, X. X. Chen, P. L. Dutton, Nature 1999, 402,47

[5] F. Polo, S. Antonello, F. Formaggio, C. Tonio, F. Maran, J. Am. Chem. Soc. 2005, 127, 492.

[6] X. Chen, L. Zhang, W. Sun, Z. Zhang, H. Liu, Y. Bu, R. I. Cukier, Phys. Chem. Lett. 2010, 1, 1637.

[7] R. A. Malak, Z. N. Gao, J. F. Wishart, S. S. Isied, J. Am. Chem. Soc. 2004, 126, 13888.
[8] T. R. Prytkova, I. V. Kurnikov, D. N. Beratan, Science 2007, 315, 622; D. N. Beratan, J. N. Onuchic, Photosynth. Res. 1989, 22, 173.

[9] B. R. Chaudhry, J. D. E. T. Wilton-Ely, A. B. Tabor, D. J. Carunana, Phys. Chem. Chem. Phys. 2010, 12, 9996; H. S. Mandal, H.B. Kraatz, Chem. Phys. 2006, 326, 246; S. Yasutomi, T. Morita, Y. Imanishi, S. Kimura, Science 2004, 304, 1944; K. J. Kise, B. E. Bowler, Inorg. Chem. 2003, 42, 3891; A. Y. Kornilova, J. F. Wishart, W. Xiao, R. C. Lasey, A. Fedorova, Y.-K. Shin, M. Y. Ogawa, J. Am. Chem. Soc. 2000, 122, 7999; M. A. Fox, E. J. Galoppini, J. Am. Chem. Soc. 1997, 119, 5277.

[10] J. S. Park, E. Karnas, K. Ohkubo, P. Chen, K. M. Kadish, S. Fukuzumi, C. W. Bielawski, T. W. Hudnall, V. M. Lanch, J. L. Sessler, Science 2010, 329, 1324; S. Fukuzumi, Prog. Inorg. Chem. 2009, 56, 49; L. M. Utschig, M. C. Thurnauer, Acc. Chem. Res. 2004, 37, 439.

[11] a) M. Cordes, A. Kötgen, C. Jasper, O. Jacques, H. Boudebous, B. Giese, Angew. Chem. 2008, 120, 3511; Angew. Chem. Int. Ed. 2008, 47, 3461; b) M. Wang, J. Gao, P. Müller, B. Giese, Angew. Chem. 2009, 121, 4296; Angew. Chem. Int. Ed. 2009, 48, 4232; c) B. Giese, M. Wang, J. Gao, M. Stoltz, P. Müller, M. Graber, J. Org. Chem. 2009, 74, 3621.

[12] M. Cordes, O. Jacques, A. Köttgen, C. Jasper, H. Boudebous, B. Giese, Adv. Synth. Catal. 2008, 350, 1053.

[13] S. Kakinoki, Y. Hirano, M. Oka, Polym. Bull. 2005, 53, 109.

[14] M. Kuemin, S. Schweizer, C. Ochsenfeld, H. Wennemers, J. Am. Chem. Soc. 2009, 131, 15474.

[15] For determination of the trans/cis ratio for the peptidyl-prolyl bond, see: H. Kessler, Angew. Chem. 1982, 94, 509; Angew. Chem. Int. Ed. Engl. 1982, 21, 512.

[16] The NMR spectra of $\mathbf{3 a}$ were recorded at $298 \mathrm{~K}$ and $400 \mathrm{MHz}$ in $\mathrm{CD}_{3} \mathrm{CN} / \mathrm{D}_{2} \mathrm{O}$ 3:1. The aromatic signals of the tyrosine in the ${ }^{1} \mathrm{H}$ NMR spectrum indicate that the investigated peptide adopts at least four different conformations, with the major one being $>50 \%$. Owing to signal overlap a more detailed analysis was not possible.

[17] C. Grathwohl, K. Wüthrich, Biopolymers 1981, 20, 2623

[18] The goal of this Communication is to determine the influence of a positive charge on the rates of intermolecular and intramolecular ET. We have therefore chosen peptides of very similar amino acid sequences, so that their conformational and dynamic flexibility is very similar. We used the identical electron acceptor, electron donor, relay amino acid, and counterions. The experiments were carried out in the same solvent mixtures at the same reaction temperature. This offers the possibility to compare the experimental data of the peptides 2-5 and 10-11, and to draw conclusions on the influence of a charge on ET steps with these peptides. If one changes a) the amino acid sequence, b) the electron acceptor, electron donor, and relay amino acid, c) the counterion, d) the polarity and/or viscosity of the solvent, and e) the reaction temperature, the absolute rates will of course also be changed by other factors than by the charge alone. Nevertheless, these influences are interesting and will be examined in future work. For a comparison with data of other groups/or assays one should pay attention to the fact that we are carrying out charge-shift experiments in the ground state.

[19] The synthesis of the unnatural amino acid with side chain 6 has been described in Ref. [12], and similar fully protected nonapeptides have already been used in Ref. [11a]. The ammonium salts were synthesized from the nonapeptides containing Cbzprotected $\mathrm{N}$-terminal amino acids. After deprotection of the $\mathrm{N}$ terminal amino acid by hydrogenation on $\mathrm{Pd} / \mathrm{C}$, the residues were dissolved in $\mathrm{CH}_{3} \mathrm{CN} / \mathrm{H}_{2} \mathrm{O}$ 3:1. Formation of the trifluoroacetates occurred during HPLC purification. The solvent mixture was an aqueous solution of $\mathrm{CH}_{3} \mathrm{CN}$ that contained $0.1 \%$ trifluoroacetic acid (gradient: $\mathrm{CH}_{3} \mathrm{CN} / \mathrm{H}_{2} \mathrm{O}$ 2:3 to $4: 1$ within $16 \mathrm{~min}$ ). The evaporation at $0.05-0.1$ mbar yielded colorless solids. MS and NMR data showed that these solids are the 
trifluoroacetates of the peptides; the $\mathrm{pH}$ value in the $\mathrm{CH}_{3} \mathrm{CN}$ / $\mathrm{H}_{2} \mathrm{O}$ mixture of the laser experiments is about 6 .

[20] The experimental setup is described in Refs. [11] and [12] as well as in the Supporting Information. Peptides (1:1 ratio) were used in 1.0 to $5.0 \mathrm{~mm}$ degassed solutions with $\mathrm{CH}_{3} \mathrm{CN} / \mathrm{H}_{2} \mathrm{O} 3: 1$ solvent mixtures. Between 40 and $1000 \mathrm{~ns}$ after the laser flash, the transient absorption spectra of the radical cation $9\left(\lambda_{\max }=\right.$ $450 \mathrm{~nm})$ and the tyrosyl radical $\left(\lambda_{\max }=408 \mathrm{~nm}\right)$ were recorded between 400 and $600 \mathrm{~nm}$. The relative concentrations were elucidated by curve analysis using MATLAB, see Ref. [21].

[21] H. Gampp, M. Maeder, C. J. Meyer, W. D. Zuberbühler, Talanta $\mathbf{1 9 8 5}, 32,95$.

[22] H. Gampp, M. Maeder, C. J. Meyer, A. D. Zuberbühler, Talanta $1985,32,257$.

[23] The synthesis of the unnatural amino acids and the peptides followed the procedure described in Ref. [11]. The ammonium salts were synthesized according to Ref. [19].

[24] The experimental setup is described in Refs. [11] and [12] as well as in the Supporting Information. Laser experiments were carried out with 2.0 to $5.0 \mathrm{~mm}$ concentrations in degassed $\mathrm{CH}_{3} \mathrm{CN} / \mathrm{H}_{2} \mathrm{O}$ 3:1 solutions. The transient absorption spectra of the radical cation $9\left(\lambda_{\max }=450 \mathrm{~nm}\right)$, the tyrosyl radical $\left(\lambda_{\max }=\right.$ $408 \mathrm{~nm}$ ), and the radical cation of the trimethoxyphenylalanine $\left(\lambda_{\max }=550 \mathrm{~nm}\right)$ were recorded $(400$ to $600 \mathrm{~nm}) 30$ to $500 \mathrm{~ns}$ after the laser flash, and their relative concentrations were elucidated by curve analysis using MATLAB, see Ref. [21]. The rates of the consecutive reaction were determined by SPECFIT, see Refs. [22] and [25].

[25] The observed decrease of the dialkoxyphenyl radical cation and increase of the tyrosyl radical in these experiments are faster than the intramolecular ET alone, because of the intermolecular reaction. Therefore we subtracted the intermolecular rates from the observed rates, according to the concentrations of these intramolecular experiments. The intermolecular ET between the electron acceptor $\mathbf{9}$ and the trimethoxyphenyl group (side chain of the relay amino acid) is so slow that it can be neglected.

[26] Since the CD spectra remained nearly unchanged by the charge (see the Supporting Information), we concluded that the positive charge does not dramatically change the PPII helical structure of the peptide. For a discussion of the influence of charges on the conformation of PPII helices see Ref. [14].

[27] The experimental setup is described in Refs. [11] and [12] as well as in the Supporting Information. The laser experiments were carried out with 1.0 to $5.0 \mathrm{~mm}$ concentrations in degassed $\mathrm{CH}_{3} \mathrm{CN} / \mathrm{H}_{2} \mathrm{O} 3: 1$ solutions. Transient absorption spectra of the radical cation $9\left(\lambda_{\max }=450 \mathrm{~nm}\right)$, the tyrosyl radical $\left(\lambda_{\max }=\right.$ $408 \mathrm{~nm}$ ), and the radical cation of the trimethoxyphenylalanine $\left(\lambda_{\max }=550 \mathrm{~nm}\right)$ were recorded $(400$ to $600 \mathrm{~nm}) 30$ to $500 \mathrm{~ns}$ after the laser flash, and their relative concentrations were elucidated by curve analysis using MATLAB, see Ref. [21]. The rates of the consecutive reaction were determined by SPECFIT, see Refs. [22] and [25].

[28] DFT calculations were carried out with Gaussian 09, using the B3LYP functional at the 6-31G(d,p) level. According to these calculations the distance $r_{1}$ between the center of the ammonium ion and the edge of the aromatic radical cation lies in the range of 2.9-3.9 $\AA$ for $\mathbf{1 1 b}$. We thank Prof. Christian Bochet for DFT calculations determining the $r_{1}$ value.

[29] G. P. Cunningham, G. A. Vidulich, R. L. Kay, J. Chem. Eng. Data 1967, 12, 336. 